

Cite this: RSC Adv., 2017, 7, 684

Received 9th October 2016

Accepted 20th October 2016

DOI: $10.1039 / c 6 r a 24960 d$

www.rsc.org/advances

\section{Synthesis of dendrobatid alkaloid (+)-167B and $(+)-209 D$ and the investigation of diastereoselectivity using DFT calculations $\uparrow$}

\author{
Wen-Hua Chiou* and Hao-Yu Chen
}

The synthesis of dendrobatid alkaloid (+)-167B and (+)-209D has been developed on the basis of the effective preparation of chiral tropinone 7-azabicyclo[3.2.1]octan-6-ol. DFT calculations have been applied to explain the observed diastereoselectivity.
Recently, indolizidine alkaloids commonly found in amphibian skin have received a great deal of attention due to their medicinal interest and diverse physiological properties. ${ }^{1}$ These indolizidine alkaloids isolated from the dendrobatid family were found to be noncompetitive blockers of the neuromuscular transmission receptor and nicotinic acetylcholine receptors, which allowed these compounds to be promising drug candidates for epilepsy, schizophrenia, Parkinson disease and Alzheimer disease. ${ }^{2,3}$ Since Daly's pioneering work in the 1970s, numerous valuable indolizidines with interesting structures have been isolated from poison-dart frogs, ${ }^{4,5}$ and 5-mono, 3,5di-substituted or 3,5-di-substituted indolizidines occupy a large portion of the discovered structures. ${ }^{6,7}$ (Fig. 1). Accordingly, novel strategies for the asymmetrical synthesis of these azabicycles continue to receive considerable attention from the synthetic community. ${ }^{8}$ As part of our interests in the synthesis of the dendrobatid alkaloids, ${ }^{9}$ we wish to demonstrate a general and efficient protocol to prepare these alkaloids. Here we report syntheses of $(+)-167 \mathrm{~B}$ and $(+)-209 \mathrm{D}$ as an application of our efficient preparation of enantiomerical tropanol, and a rationale of the observed diastereoselectivity using the DFT calculations.

Our approach to indolizidine 209D and 167B relies on efficient preparation of enantiopure 7-benzyloxycarbonylazabicyclo-[3.2.1] octan-6-one (1), readily available in both dextrorotatory and levorotatory forms by diastereomeric recrystallization of 7-azabicyclo [3.2.1]octan-6-ol with tartaric acid, and then protection of the free amine and subsequent oxidation of the hydroxyl group on basis of our previous progress $(\sim 20 \%$ overall yield after 3 steps and resolution). ${ }^{10}$ The process proved to be an effective and reliable procedure for multi-gram scale production of enantiopure

Department of Chemistry, National Chung Hsing University, Taichung, Taiwan, 402, ROC. E-mail: wchiou@dragon.nchu.edu.tw; Fax: +886-4-22862547; Tel: +886-422840411-420

$\dagger$ Electronic supplementary information (ESI) available: Experimental procedure, ${ }^{1} \mathrm{H},{ }^{13} \mathrm{C}$ NMR spectra, stereochemistry assignment and calculated geometry coordinates. See DOI: 10.1039/c6ra24960d 7-azabicyclo[3.2.1]octan-6-ol with excellent chiral integrity. Bicyclic ketone 1 was subjected to Baeyer-Villiger oxidative ring expansion with $m$-CPBA in dichloromethane to give bicyclic (-)-lactone 2, which was a quite unstable substance in either acidic or oxidative conditions. Treatment of crude lactone 2 with a mixture of $\mathrm{BF}_{3} \cdot \mathrm{OEt}_{2}$ and trimethylallylsilane resulted in cleavage of the oxabicyclic ring and formation of a transient $N$-acyl iminium ion which was captured by trimethylallylsilane, affording a 2,6disubstituted piperidine 3 as a single diastereomer in $84 \%$ yield over two steps. The relative stereo configuration would be determined in the latter stage by comparison with known structures because the nOe signals of two key methines in piperidine 3 were so ambiguous (vide infra). Lactone 2 was a useful intermediate for
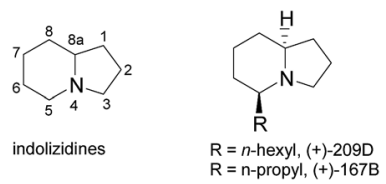

Fig. 1 Substituted structure and numbering of indolizidines.

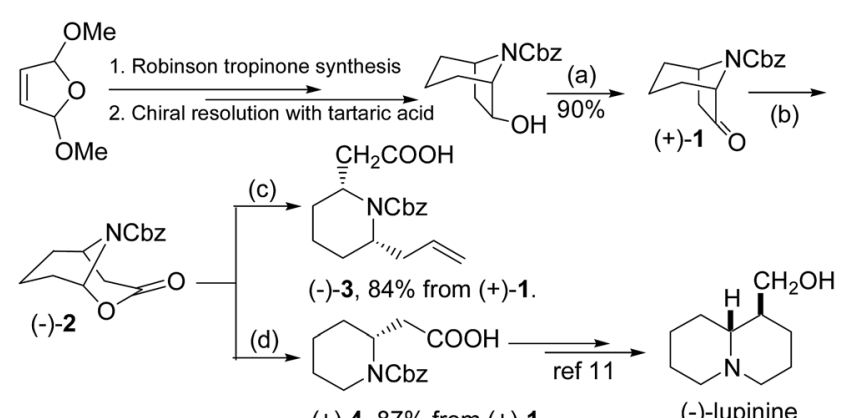

$(+)-4,87 \%$ from (+)-1.

(-)-lupinine

Scheme 1 Preparation of cis-2,6-disubstituted piperidine and piperidinyl acetic acid from chiral 6-tropanol derivative. (a) TEMPO, $\mathrm{NaOCl}$, $\mathrm{KBr}, \mathrm{NaHCO}_{3}$, acetone, $\mathrm{O}^{\circ} \mathrm{C}$. (b) $\mathrm{mCPBA}, \mathrm{Na}_{2} \mathrm{HPO}_{4}, \mathrm{CH}_{2} \mathrm{Cl}_{2}$, rt. (c) $\mathrm{BF}_{3}-$ $\mathrm{Et}_{2} \mathrm{O}, \mathrm{Me}_{3} \mathrm{SiCH}_{2} \mathrm{CH}=\mathrm{CH}_{2}, \mathrm{CH}_{2} \mathrm{Cl}_{2},-78{ }^{\circ} \mathrm{C}$. (d) $\mathrm{BF}_{3}-\mathrm{Et}_{2} \mathrm{O}, \mathrm{Et}_{3} \mathrm{SiH}$, $\mathrm{CH}_{2} \mathrm{Cl}_{2},-78^{\circ} \mathrm{C}$. 
syntheses of piperidine or quinolizidine compounds. For example, treatment with triethylsilane in the conditions would produce homopipecolic acid 4, which can be converted to (-)-lupinine, a quinolizidine alkaloids, according to the Davies's procedure. ${ }^{11}$ Here we would like to point out that enantiomerically pure 2,6disubstituted piperidine 3 would be a versatile building block for syntheses of indolizidine or quinolizidine compounds, due to the two differential side chains for further construction of the second ring moiety (Scheme 1).

To complete the synthesis of the target molecules, treatment of acid 3 with $\mathrm{SOCl}_{2}$ in cold methanol resulted in the formation of methyl ester 5 in $92 \%$ yield. The allyl portion of $\mathbf{1 8}$ was converted to a linear alcohol group using the modified Kabalka's hydroboration-oxidation procedure, ${ }^{12}$ i.e. sodium perborate, to furnish alcohol 6 in $80 \%$ overall yield. The temperature control was critical in this reaction. If the reaction temperature was higher, i.e. $0{ }^{\circ} \mathrm{C}$, it would resulted in yield loss to $40 \%$, probably due to the reduction of the ester moiety. ${ }^{13}$ Alcohol 6 was reacted with $\mathrm{MsCl}$ in the presence of $\mathrm{Et}_{3} \mathrm{~N}$ in dichloromethane to produce mesylate 7 , which was treated under ambient hydrogen pressure to remove the benzyl group, and initiated cyclization to yield indolizidine 7 in $88 \%$ yield. Having achieved the synthesis of the crucial indolizidine intermediate 7 , we continued to use the product to complete the syntheses of 209D and 167B. Reduction of ester 8 group with $\mathrm{LiAlH}_{4}$ yielded $89 \%$ yield of primary alcohol $\mathbf{9}$, which was further converted to the corresponding tosylate $\mathbf{1 0}$ in $92 \%$ yield. The resulting tosylate 10 was alkylated with dibutylcyanocuprate, a high order cyanocuprate prepared by treatment of cupper cyanide with two-fold butylithium, to furnish butylated product 11a in 64\% yield. The ${ }^{13} \mathrm{C}$ signals of 11a were identical to the reported values of $c i s-(5 R, 8 a S)$-5-hexyl-indolizidine,$^{14}$ while the specific rotation of the compound $\left([\alpha]_{\mathrm{D}}^{25}+92.6^{\circ}\left(c: 1.0, \mathrm{CH}_{2} \mathrm{Cl}_{2}\right)\right.$, literature value: $\left.+86.6^{\circ}\left(c: 1.3, \mathrm{CH}_{2} \mathrm{Cl}_{2}\right)\right)$ also compared favourably. ${ }^{15}$ Similarly, tosylate $\mathbf{1 0}$ was also reacted with dimethylcyanocuprate to produce the product $11 \mathrm{~b}$ in $61 \%$ yield, in which the ${ }^{13} \mathrm{C}$ signals and the specific rotation of $\mathbf{1 1} \mathbf{b}$ were consistent with the reported values of $c i s-(5 R, 8 a S)$-5-propyl indolizidine ${ }^{16}$ $\left([\alpha]_{\mathrm{D}}^{25}+115.0^{\circ}\left(c: 1.3, \mathrm{CH}_{2} \mathrm{Cl}_{2}\right)\right.$, literature value for its enantiomer: $-111.3^{\circ}\left(c: 1.3, \mathrm{CH}_{2} \mathrm{Cl}_{2}\right)$ ) (Scheme 2). ${ }^{15}$

To explain the resulting stereochemistry outcome, we propose the addition proceeded in a two-step manner. ${ }^{17} \mathrm{BF}_{3}$-mediated coordination on the lactone moiety immediately results in the ring cleavage, and therefore the formation of the transient $\mathrm{N}$ acyliminium intermediate. Subsequent silane addition on the intermediate furnishes the cis-2,6-disubstituted piperidine stereoselectively. First of all, we consider the prototype reaction in which trimethylallylsilane reacts on a substituent-free $\mathrm{N}$ methoxycarbonyl $\Delta^{1}$-piperideinium. Trimethylallylsilane may take either axial or equatorial approach to react on the piperideinium bearing either s-trans or s-cis configuration, which is achieved by rotation of the carbamate bond..$^{18}$ Thus, we perform the DFT calculations at the level of B3LYP/6-31++G (d, p) to obtain all four possible TS geometries during the silane addition (Fig. 2).

The results in Table 1 have disclosed the stabilities of these four transition states appear to be concerned with the

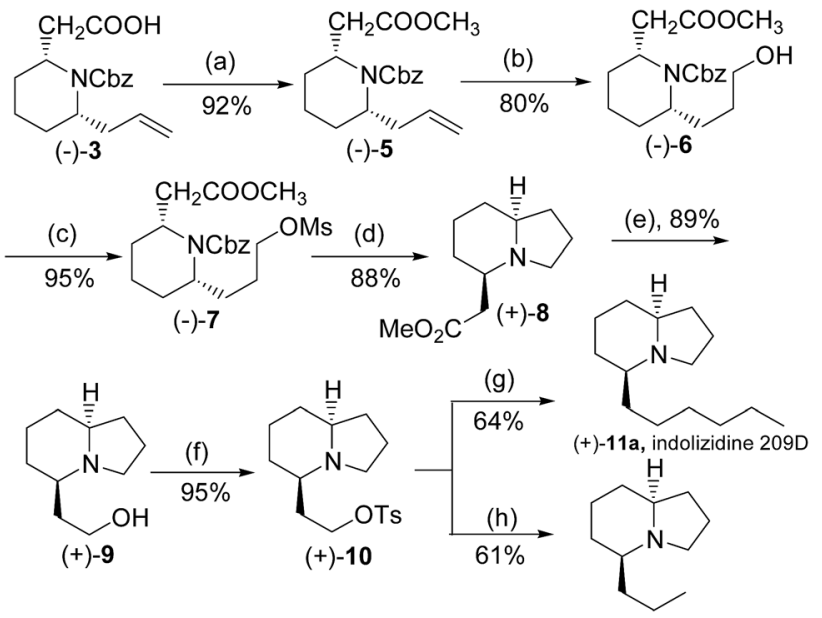

(+)-11b, indolizidine 167B

Scheme 2 Synthesis of indolizidine 167B and 209D. (a) SOCl, $\mathrm{MeOH}$, $0{ }^{\circ} \mathrm{C}$. (b) (i) $\mathrm{BH}_{3}-\mathrm{THF}, \mathrm{THF},-50{ }^{\circ} \mathrm{C}$, (ii) $\mathrm{NaBO}_{3}, \mathrm{H}_{2} \mathrm{O}$, rt. (c) $\mathrm{MsCl}_{2} \mathrm{Et}_{3} \mathrm{~N}$, $\mathrm{CH}_{2} \mathrm{Cl}_{2}$, rt. (d) $\mathrm{Pd} / \mathrm{C}, \mathrm{H}_{2}, \mathrm{Et}_{3} \mathrm{~N}, \mathrm{MeOH}$, rt. (e) $\mathrm{LiAlH}_{4}, \mathrm{THF}$, rt. (f) $\mathrm{TsCl}, \mathrm{Et}_{3} \mathrm{~N}$, $\mathrm{CH}_{2} \mathrm{Cl}_{2}$, rt. (g) CuCN, MeLi, $\mathrm{Et}_{2} \mathrm{O}, 0^{\circ} \mathrm{C}$. (g) $\mathrm{CuCN}, n-\mathrm{BuLi}, \mathrm{Et}_{2} \mathrm{O},-78^{\circ} \mathrm{C}$.

piperideinium conformations and electrostatic attractions between two major dipoles, the iminium and the carbonyl groups. The s-cis-configuration guarantees best coulombic attraction by disposing the most positive iminium carbon atom (C-2) as close in space to the most negative carbonyl oxygen atom (O-1) as possible. ${ }^{19}$ In addition, with a pseudo-chair conformation, $\mathrm{TS}_{\mathrm{ax}-\text {-cis }}$ and $\mathrm{TS}_{\mathrm{ax} \text {-trans }}$ structures involved with the axial approach are more stable than $\mathrm{TS}_{\text {equ-cis }}$ and $\mathrm{TS}_{\text {equ-trans }}$ which bears with a twist boat conformation. In fact, the conformation distortion can be best characterized and evaluated by the dihedral angle $\phi_{1}$, the angle of the iminium hydrogen and the equatorial hydrogen at the C-3 position (Table 1). Severe deviation from the typical gauche angle $\left(\sim 60^{\circ}\right)$ is noticed $\left(\Delta \phi_{1} \sim 45^{\circ}\right)$ and strong eclipsing interaction is also
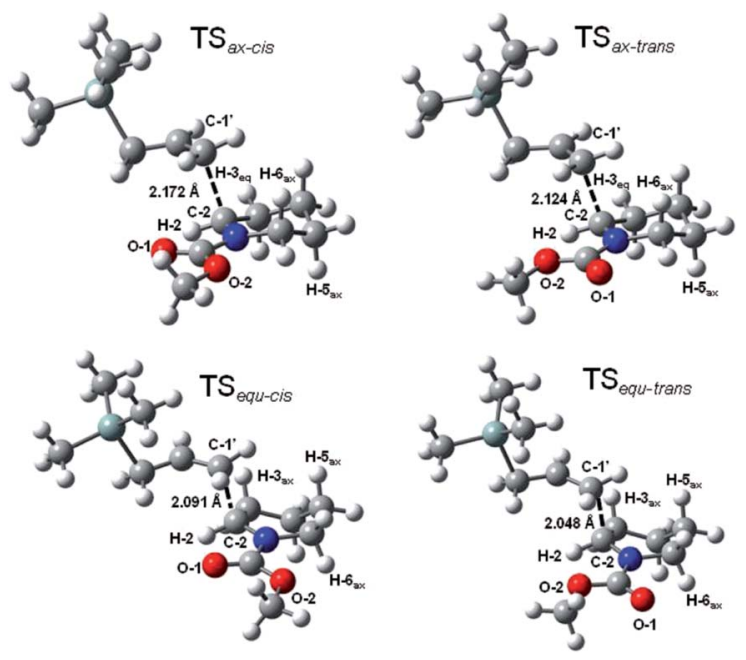

Fig. 2 Four TS geometries describing axial and equatorial silane additions on $\mathrm{N}$-methoxycarbonylpiperidenium with $\mathrm{s}$-cis and $\mathrm{s}$-trans configuration. 
Table 1 Relative energies, imaginary frequency, dihedral angle and distance in four TS geometries ${ }^{a}$

\begin{tabular}{lllll}
\hline & Rel $E$ & $\operatorname{Imag} \nu$ & $\phi_{1}$ & $\mathrm{C}_{2}-\mathrm{C}_{1^{\prime}}$ \\
\hline TS $_{\text {ax-cis }}$ & 0.0 & 208 & 55.0 & 2.172 \\
TS $_{\text {ax-trans }}$ & +2.3 & 232 & 54.5 & 2.174 \\
TS $_{\text {equ-cis }}$ & +3.0 & 246 & 15.2 & 2.091 \\
TS $_{\text {equ-trans }}$ & +5.8 & 259 & 15.8 & 2.048
\end{tabular}

${ }^{a}$ Energy in $\mathrm{kcal} \mathrm{mol}^{-1}$, imagine frequency in $\mathrm{cm}^{-1}, \phi_{1}$ is the dihedral angle $\angle \mathrm{H}_{2}-\mathrm{C}_{2}-\mathrm{C}_{3}-\mathrm{H}_{3 \text { equ }}$, distance in $\AA$.

expected. A large angle deviation implies a local eclipse conformation, and naturally results in a relative unstable twist boat conformation, while a small deviation ensures a stable pseudo-chair conformation. Thus, we conclude that the axial addition on the s-cis-carbamate substrate dominates among these four possible reaction routes since the $\mathrm{TS}_{\mathrm{ax}-c i s}$ is the most stable among the four possible transition state geometries. It is worthy to point out that the electrostatic interactions and the ring conformations seem to contribute roughly equally in the stabilities of these transition states, and a longer reaction distance in the transition state geometries will be allowed in case of that either beneficial factor is hold.

Next, we consider two possible syn and anti approach in the axial addition manner on the $Z$ - $N$-methoxycarbonyl $\Delta^{1}$-piperideinium bearing an acetic group at the C-6 position on the basis of the favored transition state $\mathrm{TS}_{\mathrm{ax}-Z}$, and obtain two TS structures $\mathrm{TS}_{s y n}$ and $\mathrm{TS}_{\text {anti }}$ which lead the cis- and trans-2,6disubstituted adduct respectively (Fig. 3). The results show the $\mathrm{TS}_{\text {syn }}$ is favoured over $\mathrm{TS}_{\text {anti }}$ by $8.1 \mathrm{kcal} \mathrm{mol}^{-1}$, indicating the silane addition prefers to proceed in "syn addition" to yield the cis-2,6-disubstituted adduct.

In the $\mathrm{TS}_{s y n}$ structure, the piperideinyl ring with the axial substituent on the C- 6 position keeps a less strained conformation because of small deviations from the parent structure


\begin{tabular}{crrr}
\hline & $\mathrm{TS}_{\text {svn }}$ & $\mathrm{TS}_{\text {anti }}$ & \multicolumn{1}{c}{$\mathrm{TS}_{\mathrm{ax}-\mathrm{Z}}$} \\
\hline $\mathrm{rel} \mathrm{E}$ & 0.0 & 8.1 & ----- \\
$\mathrm{C}_{2}-\mathrm{C}_{1^{\prime}}$ & 1.951 & 1.870 & 2.172 \\
$\phi_{1}$ & 59.5 & 55.3 & 55.0 \\
$\phi_{2}$ & 162.2 & 144.1 & 168.2 \\
$\phi_{3}$ & 2.7 & 15.0 & 0.5 \\
$\phi_{4}$ & 176.7 & 161.8 & 179.6 \\
\hline
\end{tabular}

Fig. 3 syn and anti approach TS geometries with axial silane addition on 6 -substituted $N$-methoxycarbonyl $\Delta^{1}$-piperideinium. Energy in kcal mol $^{-1}$, distance in $\AA$, $\phi_{1}: \angle \mathrm{H}_{2}-\mathrm{C}_{2}-\mathrm{C}_{3}-\mathrm{H}_{3 \text { equ }}, \phi_{2}: \angle \mathrm{C}_{5 a x}-\mathrm{C}_{5}-\mathrm{C}_{6}-\mathrm{C}_{6 a x}$, $\phi_{3}: \angle \mathrm{C}_{2}-\mathrm{N}-\mathrm{C}=\mathrm{O}_{1}, \phi_{4}: \angle \mathrm{C}_{2}-\mathrm{N}-\mathrm{C}-\mathrm{OMe}$.
$\left(\Delta \phi_{2}=6^{\circ}\right)$. In addition, analysis of the $\mathrm{TS}_{\text {syn }}$ structure reveals good planar geometry in the carbamate group $\left(\phi_{3}=2.7^{\circ}\right.$ and $\phi_{4}$ $=176.7^{\circ}$ ), suggesting the double bond character in the carbamate remains nearly intact during silane approaching. The distortion of the piperideinium ring is best illustrated by dihedral angle $\phi_{2}$, the angle of the two axial substituents at the C-5 and C-6 position, while dihedral angle $\phi_{3}$ and $\phi_{4}$ are used to describe the planarity of the carbamate. Since the syn approach to the cis-2,6-disubstituted piperidine adduct does not distort either the planarity or the ring conformation, a long distance between $\mathrm{C}_{1^{\prime}}-\mathrm{C}_{2}$ in transition state has been allowed. Comparing to the $\mathrm{TS}_{\text {syn }}$ geometry, the $\mathrm{TS}_{\text {anti }}$ geometry shows that the anti addition does not only alter the dihedral angle $\phi_{2}$ to 144 degree, but also change the dihedral angle $\phi_{4}$ to 162 degree, significantly attenuate the planarity of the carbamate group $\left(\phi_{3}=\right.$ $15.0^{\circ}$ and $\left.\phi_{4}=161.8^{\circ}\right)$ and twist the conformation of the $\Delta^{1}$ piperideinium ring to suffer more strain compared to that in the non-substituent case $\left(\Delta \phi_{2}=24.1^{\circ}\right)$. Both the piperideinyl moiety and the carbamate moiety need to be distorted to accommodate the equatorial substituent as the anti approach progressed. Thus, anti addition will result in the instability of the corresponding transition state, and the absence of the 2,6trans product. The traditional explanation argues that a stable reactant conformation dominates stereo outcome: since the $\mathrm{A}^{1,3}$-strain exerted from a substituent on the nitrogen has imposed an pseudoaxial orientation on the C-6 substituent as a stable reactant conformation, only an nucleophilic addition is only allowed from the least hindered face, i.e. an axial addition, to afford the cis-2,6-disubstituted product. ${ }^{20}$

Our calculations provide different perspectives, in which the stable transition state is crucial to determine the possible reaction routes. Three major factors, distortion in the ring conformation, intactness of carbamate planarity and electrostatic attraction, contribute to the stabilities of the transition states and dominate the silane addition to proceed in the synapproach on the C-6 substituted $\Delta^{1}$-piperideinium with s-ciscarbamate configuration in the axial manner.

In conclusion, we have presented syntheses of two dendrobated alkaloids, (+)-indolizidine 209D and (+)-indolizidine 167B, featuring applications of readily available enantiomerical 6-tropinonol to the 2,6-disubstituted piperidines and 5-substituted indolizidines via Baeyer-Villiger oxidation. The DFT results described above provides a transition state-based rationale of the observed cis-selectivity for the formation of only cis-2,6-disubstituted piperidine product. Further applications to interesting targets and extension of calculations are under active investigation.

\section{Acknowledgements}

The research was supported by the National Science Council, Taiwan (NSC104-2113-M-005-004), and National Center for High-Performance Computing for computation facilities.

\section{Notes and references}

1 (a) J. P. Michael, Nat. Prod. Rep., 2008, 25, 139; (b) J. W. Daly and T. F. Spande, Alkaloids: Chemical and Biological 
Perspectives: Amphibian Alkaloids: Chemistry, Pharmacology and Biology, Wiley Interscience, New York, 1986.

2 N. Toyooka, T. Hirosho, K. Soushi, Z. Dejun, K. Masashi, K. Ikuto, S. Toshiyasu and N. Hideo, Curr. Chem. Biol., 2007, 1, 87.

3 A. M. Lourenco, P. Maximo, L. M. Ferreira and M. M. A. Pereira, Stud. Nat. Prod. Chem., 2002, 27, 233.

4 J. W. Daly, H. M. Garraffo, T. F. Spande, M. W. Decker, J. P. Sullivan and M. Williams, Nat. Prod. Rep., 2000, 17, 131.

5 J. W. Daly, T. F. Spande and H. M. Grraffo, J. Nat. Prod., 2005, 68, 1556.

6 R. A. Saporito, T. F. Spande, H. M. Garraffo and M. A. Donnelly, Heterocycles, 2009, 79, 277.

7 F. Abeis, C. Lindermann, E. Koch and C. Schneider, Org. Lett., 2012, 14, 5972.

8 For selected excellent reviews of syntheses of enantionmerical indiolizidines, see (a) S. M. Bronner, G.-Y. J. Im and N. K. Garg, in Heterocycles in Natural Product Synthesis, ed. K. C. Majumdar and S. K. Charropadhyay, 2011, pp. 221-265; (b) R. Lazzaroni and R. Settambolo, Chirality, 2011, 23, 730; (c) A. Brandi, F. Cardona, S. Cicchi, F. M. Cordero and A. Goti, Chem.Eur. J., 2009, 15, 7808; (d) S. Agarwal, S. Cämmerer, S. Filali, W. Fröhner, J. Knöll, M. P. Krahl, K. R. Reddy and H.-J. Knölker, Curr. Org. Chem., 2005, 9, 1601; (e) S. Hanessian, E. Therrien, J. S. Warrier and G. Charron, Heterocycles, 2006, 70, 461; $(f)$ M. S. M. Timmer, S. H. L. Werheist, G. M. Grotenbreg, M. Overhand and H. S. Overkleefe, Pure Appl. Chem., 2005, 77, 1173.

9 W.-H. Chiou and Y.-M. Chiang, RSC Adv., 2014, 4, 11444.

10 W.-H. Chiou, G.-T. Chen, C.-L. Kao and Y.-K. Gao, Org. Biomol. Chem., 2012, 10, 2518.

11 S. G. Davies, A. M. Fletcher, E. M. Foster, I. T. T. Houlsby, P. M. Roberts, T. M. Schofiled and J. E. Thomson, Chem. Commun., 2014, 50, 8309.

12 G. W. Kabalka, T. M. Shoup and N. M. Goudgaon, J. Org. Chem., 1989, 54, 5930.
13 E.-K. Shin, H. J. Kim, Y. Kim, Y. Kim and Y. S. Park, Tetrahedron Lett., 2006, 47, 1865.

14 (a) For the reported ${ }^{13} \mathrm{C}-\mathrm{NMR}$ peak values of cis-209D, see R. T. Yu, E. E. Lee, G. Malik and T. Rovis, Angew. Chem., Int. Ed., 2009, 48, 2379; (b) For the reported ${ }^{13} \mathrm{C}-\mathrm{NMR}$ peak values of trans-209D, see C. Alegret and A. Riera, J. Org. Chem., 2008, 73, 8661.

15 P. G. Reddy and S. Baskaran, J. Org. Chem., 2004, 69, 3093.

16 (a) For the reported ${ }^{13} \mathrm{C}-\mathrm{NMR}$ peak values of $c i s-167 \mathrm{~B}$, see A. Kapat, E. Nyfeler, G. T. Giuffredi and P. Renaud, J. Am. Chem. Soc., 2009, 131, 17746; (b) For the reported ${ }^{13}$ C-NMR peak values of trans-167B, see A. K. Saikia, K. Indukuri and J. Das, Org. Biomol. Chem., 2014, 12, 7026.

17 (a) W. N. Speckamp and M. J. Moolenaar, Tetrahedron, 2000, 56, 3817; (b) R. Remuson, Beilstein J. Org. Chem., 2007, 3, 1; (c) M. Node, A. Itoh, Y. Masaki and K. Fuji, Heterocycles, 1991, 32, 1705.

18 Calculations also discloses that the $s$-cis conformer is more stable than the $s$-trans one by $0.6 \mathrm{kcal} \mathrm{mol}^{-1}$ in free rotation of carbon-nitrogen bond of a substituent-free $\mathrm{N}$ methoxycarbonyl $\Delta^{1}$-piperideinium. It can be also rationalized by the concept of "dipole cancellation", a critical factor in nonpolar solvents. The rotation energy barriers from the $s$-cis form to the $s$-trans form are about 6.1 to $6.3 \mathrm{kcal} \mathrm{mol}^{-1}$ depending on which ways of two possible rotations of the carbonyl group, moving through either the equatorial substituent side at the C-6 or the axial one.

19 (a) I. Flaming, Molecular Orbitals and Organic Chemical Reactions, John Wiley \& Sons, 2009; (b) E. V. Anslyn and D. A. Dougherty, in Modern Physical Organic Chemistry, University Science Books, 2006, p. 123.

20 (a) T. Luker, H. Hiemstra and W. N. Speckamp, J. Org. Chem., 1997, 62, 3592; (b) M. P. Cassidy and A. Padwa, Org. Lett., 2004, 6, 4029; (c) S.-S. P. Chou, T.-H. Yang, W.-S. Wu and T.-H. Chiu, Synthesis, 2011, 759. 